\title{
Use of Padlock Probes and Rolling Circle Amplification (RCA) for Rapid Identification of Trichophyton Species, Related to Human and Animal Disorder
}

\author{
Hamideh Zakeri ${ }^{1}$; Tahereh Shokohi ${ }^{2,3,}$; Hamid Badali ${ }^{2,3}$; Saba Mayahi ${ }^{3}$; Mojtaba Didehdar ${ }^{1,4}$ \\ ${ }^{1}$ Student Research Committee, Faculty of Medicine, Mazandaran University of Medical Sciences, Sari, IR Iran \\ ${ }^{2}$ Invasive Fungi Research Center (IFRC), Mazandaran University of Medical Sciences, Sari, IR Iran \\ ${ }^{3}$ Department of Medical Mycology and Parasitology, Mazandaran University of Medical Sciences, Sari, IR Iran \\ ${ }_{4}^{4}$ Arak Medical Faculty, Arak University of Medical Sciences, Arak, IR Iran \\ ${ }^{*}$ Corresponding author: Tahereh Shokohi, Invasive Fungi Research Center (IFRC), Mazandaran University of Medical Sciences, Sari, IR Iran. Tel: +98-1133543781, Fax: 98-1513543248, \\ E-mail: shokohi.tahereh@gmail.com
}

Received: March 23, 2014; Revised: August 7, 2014; Accepted: August 27, 2014

Background:The high degree of phenotypic similarity among Trichophyton species makes their identification difficult.

Objectives: The current study aims to establish the use of rolling circle amplification (RCA) based on internal transcribed spacer ribosomal DNA (ITS rDNA) as a powerful, simple, and rapid procedure for distinguishing closely related organisms, and specifically to identify Trichophyton species, which cause human and animal disorders.

Materials and Methods: A total of sixty-one isolates belonging to three species of Trichophyton were identified to the species level based on microscopic and macroscopic examinations and their ITS rDNA regions were sequenced. Three specific circular oligonucleotide probes targeting the ITS1 and ITS2 regions were designed to differentiate Trichophyton rubrum, T. mentagrophytes, and T. tonsurans.

Results: Of the 61 putative Trichophyton clinical isolates, 52 were identified to the species level. The most common species was $T$. mentagrophytes var. interdigitale (31 isolates), followed by T. rubrum (11 isolates), T. tonsurans ( 9 isolates), and T. violaceum ( 1 isolates); moreover, 9 isolates were identified as non-Trichophyton species. The RCA method correctly identified four Trichophyton species and was $100 \%$ specific for each species. Neither cross-reaction between the examined species of Trichophyton nor false positive or false negative results were observed.

Conclusions: Species identification of Trichophyton is crucially important for epidemiological and phylogenetic purposes and for genotype delineation. RCA based on ITS polymorphisms can be used to generate identification barcodes and as an alternative to DNA sequencing; it is a very fast, specific, and economical tool for species identification.

Keywords: Identification; Trichophyton; Oligonucleotide Probes; Rolling Circle Amplification (RCA); DNA, Ribosomal

\section{Background}

Members of the genus Trichophyton are the most common agents of dermatophytosis in humans and other animals, and are associated with a variety of clinical aspects (1-3). The most frequent species of dermatophytes are Trichophyton mentagrophytes, T. tonsurans, and T. rubrum, and these species cause a multiplicity of cutaneous disorders. They are keratinophilic fungi that attack keratinized tissue and cause a wide spectrum of clinical manifestations that vary from mild to severe, but infections are not life-threatening. Owing to the high degree of phenotypic similarity among species, identification is difficult. Conventional approaches for species-level identification in the diagnostic laboratory are based on morphological and physiological criteria, require several days or weeks to obtain results, and are frequently unspecific. To overcome these problems, molecular techniques have recently been developed to rapidly and precisely identify species of Trichophyton that potentially cause human infection.

Numerous recent articles and reviews have exhaustively discussed the various molecular techniques available for dermatophyte species identification. Molecular tools, such as sequencing of the internal transcribed spacer (ITS) region of ribosomal DNA(rDNA), have shown promise for species identification in all genera of dermatophytes, and is relatively expensive (4-7). Moreover, ITS-based analyses have found that sequence variation is limited to only one or a few single nucleotide polymorphisms (SNPs) between certain species, e.g., T. tonsurans and T. equinum or T. rubrum and T. soudanense (7). This limited genetic variation suggests that the development of alternative molecular tools with sufficient specificity, reproducibility, and sensitivity is highly necessary (8). Rolling-circle amplification (RCA) is a powerful and simple

Copyright (C) 2015, Ahvaz Jundishapur University of Medical Sciences. This is an open-access article distributed under the terms of the Creative Commons Attribution-NonCommercial 4.0 International License (http://creativecommons.org/licenses/by-nc/4.0/) which permits copy and redistribute the material just in noncommercial usages, provided the original work is properly cited. 
procedure for distinguishing closely related taxa at the species level; it is based on the rolling replication of short single-stranded DNA circles via specific DNA polymerases under isothermal conditions. This enables the detection of target nucleic acid sequences, including SNPs, with high specificity (9-12).

\section{Objectives}

The objective of the current study is to establish the use of RCA based on ITS rDNA to rapidly identify Trichophyton species that potentially cause human and animal disorders.

\section{Materials and Methods}

\subsection{Fungal Strains}

In the current study, all samples were obtained from different human sources that were referred to the mycology laboratory at Tooba Clinic, Mazandaran University of Medical Sciences, Iran and were suspected dermatophytosis cases. The study protocol was approved by the Medical Research Ethics Committee of Mazandaran University of Medical Sciences (Ethical No. 90-2-28/90-14) and since the laboratory diagnosis was part of the patients' routine care, informed consent for research purposes was not specifically obtained. A total of 61 isolates belonging to three species of Trichophyton including the three reference strains T. rubrum (Centraalbureau voor Schimmelcultures: CBS 130927), T. mentagrophytes var. interdigitale (National Biological Resource Center: NBRC 5812), and T. tonsurans (NBRC 5928) were examined.

\subsection{Morphological Identification}

All clinical samples from suspected patients were cultured on plates of Sabouraud glucose agar (Merck, Darmstadt, Germany), with chloramphenicol and cycloheximide (SCC). The plates were incubated for $4-6$ weeks at $28^{\circ} \mathrm{C}$. All colonies were examined macroscopically and microscopically in Lactophenol Cotton Blue. The Trichophyton species were identified based on microscopic morphology and in vitro tests including urease and hair perforating tests, as required.

\subsection{Molecular Identification}

\subsubsection{DNA Extraction}

First, Trichophyton species were grown on Sabouraud dextrose agar (SDA, Difco, USA) for 10 days at $24^{\circ} \mathrm{C}$ in dark conditions. A sterile blade was used to scrape off the hyphae from the surface of the plate, which were transferred to a 2-mL Eppendorf tube containing $1 \mathrm{~mL}$ of lysis buffer (200 mM Tris-HCl, pH 8.0, with 25 mM EDTA, 0.5\% [wt/vol] sodium dodecyl sulfate, and $250 \mathrm{mM} \mathrm{NaCl}$ ). Cells were mechanically disrupted with a conical grinder for approximately $1 \mathrm{~min}$, and then incubated at $100^{\circ} \mathrm{C}$ for 15 min. Next, $150 \mu \mathrm{L}$ of 3.0 M sodium acetate buffer was added, the mixture was vortexed and incubated for $10 \mathrm{~min}$ at $-20^{\circ} \mathrm{C}$, and the solution was mixed and centrifuged for $5 \mathrm{~min}$ at 10,000 $\times \mathrm{g}$. The supernatant was transferred to a new tube and phenol/chloroform (1:1, v/v) was used for extraction. DNA was allowed to precipitate with an equal volume of isopropanol for $10 \mathrm{~min}$ at $-20^{\circ} \mathrm{C}$ and then centrifuged for $5 \mathrm{~min}$ at 10,000 rpm. The pellets were washed with cold $70 \%$ ethanol, dried at room temperature, resuspended in $97.5 \mathrm{~mL}$ of TE-buffer with $2.5 \mathrm{~mL}$ of RNAse (20 $\mathrm{U} / \mathrm{mL}$ ), and incubated for $5 \mathrm{~min}$ at $37^{\circ} \mathrm{C}$. DNA extracts were stored at $-20^{\circ} \mathrm{C}$ prior to use.

\subsubsection{ITS rDNA Amplification}

The ribosomal DNA internal transcribed spacers (i.e., the ITS region of rDNA) were amplified using the universal primers ITS1 (5'-TCC-GTAGGTGAACCTGCGG-3') and ITS4 (5'-TCCTCCGCTTATTGATATGC-3') (13). PCR reactions were performed on a TC-312 thermal cycler (Techne, Duxford, Cambridge, United Kingdom) in 25-mL volumes containing $25 \mathrm{ng}$ of template DNA, $2.5 \mathrm{~mL}$ of reaction buffer ( 0.1 M Tris- $\mathrm{HCl}, \mathrm{pH}$ 8.0, $0.5 \mathrm{M} \mathrm{KCl}, 15 \mathrm{mM} \mathrm{MgCl}$, 0.1\% gelatin, and $1 \%$ Triton X-100), $0.2 \mathrm{mM}$ of each dNTP, and $2.0 \mathrm{U}$ of Taq DNA polymerase. Amplification was performed as follows: 2 min at $94^{\circ} \mathrm{C}$ for primary denaturation, followed by 35 cycles at $94^{\circ} \mathrm{C}(45 \mathrm{~s}), 52^{\circ} \mathrm{C}(30 \mathrm{~s})$, and $72^{\circ} \mathrm{C}(120 \mathrm{~s})$, with a final 7-min extension step at $72^{\circ} \mathrm{C}$. PCR products were visualized by $1.5 \%(\mathrm{w} / \mathrm{v})$ agarose gel electrophoresis in TBE buffer, stained with ethidium bromide $(0.5 \mu \mathrm{g} / \mathrm{mL})$, and photographed under UV transillumination.

\subsubsection{Primers and Padlock Probes Used for RCA}

The approximate length of the three specific circular oligonucleotide probes for T. rubrum, T. mentagrophytes var. interdigitale, and T. tonsurans used in this study was 96 to $102 \mathrm{bp}$, and comprised two target-complementary segments connected by a genetic linker sequence. They were previously designed by Kong et al. (8) to minimize similarity between closely related strains and to allow primer binding during RCA. However, specific padlock probes targeting the ITS1 and ITS2 regions were modified, and RCA primers designed to specifically bind the linker region of the probes were synthesized by Anaspec Inc. (San Jose, CA, USA) (Table 1).

\subsubsection{Ligation of Padlock Probes}

Purified PCR products $(1 \mu \mathrm{L})$ were mixed with $2 \mathrm{U}$ Pfu (1 $\mu \mathrm{L})$ DNA ligase (Bioneer ISO 13485, Alameda, CA, USA) and $1 \mu \mathrm{L}$ of padlock probe in $500 \mathrm{mM}$ Tris- $\mathrm{HCl}$ ( $\mathrm{pH} 7.5), 50 \mathrm{mM}$ $\mathrm{KCl}, 100 \mathrm{mM} \mathrm{MgCl} 2,2.5 \mu \mathrm{L} / \mathrm{mL}$ bovine serum albumin (pH 7.5), 10 mM ATP, and 50 mM DTT with a total reaction volume of $10 \mu \mathrm{L}$. Multiple cycle ligations were conducted with one cycle of denaturation at $94^{\circ} \mathrm{C}$ of $5 \mathrm{~min}$, followed by five cycles at $94^{\circ} \mathrm{C}$ for $30 \mathrm{~s}$ and $4 \mathrm{~min}$ of ligation at $62^{\circ} \mathrm{C}$. 
Table 1. Oligonucleotide Padlock Probes and Primers Used for RCA

\begin{tabular}{|c|c|}
\hline Probes/Primers & Sequence \\
\hline T. tonsurans & $\begin{array}{c}\text { (5'p-AAGCCGGAATCGCGGCCTGGgatcatgcttcttcggtgcccattacgaggtgcggatagctaccgcgcagacacgatagtc- } \\
\text { taCCCATTCGCCTAGA-3') }\end{array}$ \\
\hline T. rubrum & $\begin{array}{l}\text { (5'p-TTGGCTGCCCATTCGCCTAGgatcatgcttcttcggtgcccattacgaggtgcggatagctaccgcgcagacacgatagtctaTGAGGGC- } \\
\text { GCTGAA-3') }\end{array}$ \\
\hline T. mentagrophytes & $\begin{array}{l}\text { (5’p-AGCCACTAAAGAGAGGCTCGCgatcatgcttcttcggtgcccattacgaggtgcggatagctaccgcgcagacacgatagtctaCGGTC- } \\
\text { CAGCGTTT-3') }\end{array}$ \\
\hline RCA1 & (5'-ATGGGCACCGAAGAAGCA-3') \\
\hline RCA2 & (5'-CGCGCAGACACGATA-3') \\
\hline
\end{tabular}

\subsubsection{Hyper-Branched or Rolling Circle Amplification Reactions}

RCA reactions were performed in a $25-\mu \mathrm{L}$ volume containing 8 U of Bst DNA Polymerase (New England BioLabs, Ipswich, MA, USA), $200 \mu \mathrm{M}$ deoxynucleoside triphosphate mix, $1 \mu \mathrm{L}$ of each RCA primer, and $2 \mu \mathrm{L}$ of ligation product. Probe signals were amplified by incubation at $65^{\circ} \mathrm{C}$ for 60 min and $85^{\circ} \mathrm{C}$ for $2 \mathrm{~min}$, and the accumulation of doublestranded DNA products was detected by electrophoresis on $1 \%$ agarose containing ethidium bromide (Sigma, St. Louis, MO, USA). Ladder-like patterns were interpreted as positive reactions, while negative reactions showed no illumination.

\section{Results}

The Trichophyton species were not easily differentiated from each other based on mycological criteria. Of the 61 clinically isolated samples, 31 isolates (50.8\%) were identified as T. mentagrophytes var interdigitale, 11 isolates (18.2\%) as T. rubrum, 9 isolates (14.7\%) as T. tonsurans, and 1 isolate as (1.8\%) T. violaceum. Moreover, 9 isolates (14.7\%) were identified as non-Trichophyton species. RCA and subsequent detection by gel electrophoresis yielded positive results, and the test proved to be $100 \%$ specific for each species. Neither cross-reaction between the examined species of Trichophyton nor false positive or false negative results were observed (Figure 1). Positive RCA reactions were visualized by UV irradiation as ladder-like, strongly illuminated smears on $1.2 \%$ agarose gels, while the background remained clean for negative reactions (Figure 1 ). RCA reactions were performed for all isolates; 45 isolates (73.3\%) were positive for the probe specific to T. mentagrophytes, 8 isolates (13.1\%) for the probe specific to T. rubrum, and 4 isolates (6.6\%) for the probe specific to T. tonsurans (Figure 1). However, four isolates ( $8.6 \%$ ) did not test positive using any of the three species-specific padlock probes and probably represented separate dermatophyte species.

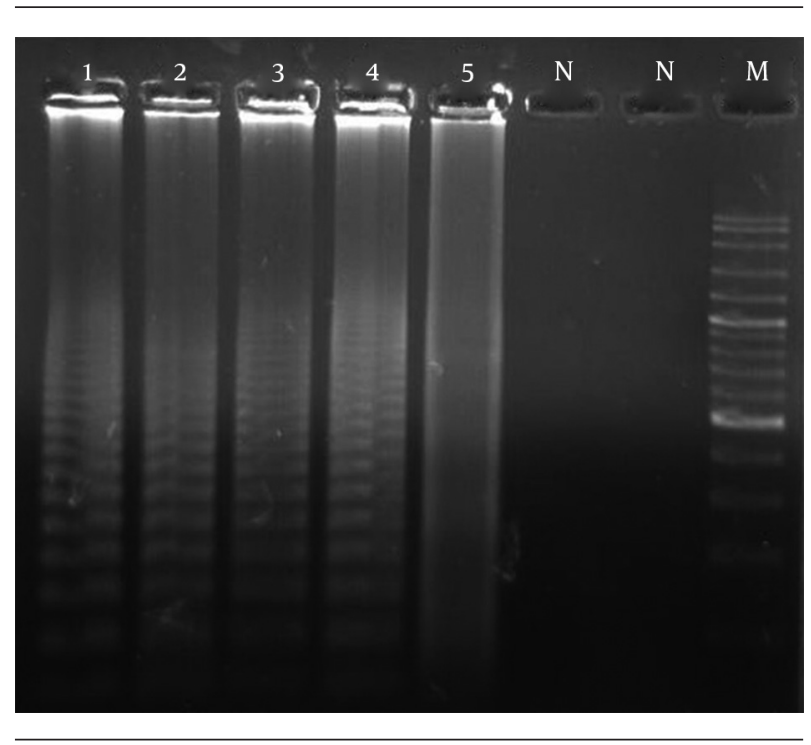

Figure 1. Representative Gel of Specificity of RCA Amplification Probes. 1) Positive reaction standard for T. mentagrophytes var. interdigitale (NBRC5812) with the T. mentagrophytes var. interdigitale probe; 2 ) Positive reaction standard for T. rubrum (CBS130927) with the T. rubrum probe; 3) Positive reaction standard for T. tonsurans (NBRC5928) with the T. tonsurans probe; 4) Positive reaction for an unknown case with the $T$. mentagrophytes var. interdigitale probe; 5) Positive reaction for an unknown case with the T. rubrum probe; N) Negative reaction standard for T. tonsurans (NBRC5928) with the T. rubrum probe; N) Negative reaction standard for T. rubrum (CS 82) with the T. mentagrophytes var. interdigitale probe; M) Ladder (100 bp).

\section{Discussion}

Members of the genus Trichophyton are the most common agents of dermatophytosis in humans and other animals. Identification of Trichophyton species is essentially based on macroscopic and microscopic observations of their morphological features; however, the identification is complicated and laborious owing to the morphological similarity, polymorphism and cultural variability of Trichophyton species. Thus, accurate identification is timeconsuming and requires a significant level of knowledge 
and technological expertise (4). ITS-based analyses have found that sequence variation is limited to only one or a few SNPs between certain species, such as between T. tonsurans and T. equinum, and between T. rubrum and T. soudanense (7). Although sequencing of the ITS region of rDNA is currently the gold standard for the identification of Trichophyton species and relatives, the technique is relatively expensive and time-consuming, and is impractical for the analysis of large numbers of isolates for epidemiological studies. To overcome these problems, molecular biology-based techniques have been developed for rapid and accurate species determination.

Recently, isothermal techniques, such as loop-mediated amplification and RCA, have been applied for rapid identification. The use of circularizable oligonucleotides or padlock probes is based on the rolling replication of short single-stranded DNA circles by certain DNA polymerases under isothermal conditions to detect target nucleic acid sequences, including SNPs, with high specificity (9-16). Such probes comprise two sequences that are complementary to the 5' and 3 ' termini of the target sequence joined by a genetic linker region. Upon hybridization to the target, the two probe ends become juxtaposed and are joined by DNA ligase to form a closed molecule. The intensity of the signal generated by the probe is then increased exponentially by hyper branching or RCA, and 109-fold signal amplification of each circle can be achieved within 90 min $(8,13,17)$. The RCA technique was initially established by Fire and Xu (18) and Liu et al. (19) and is an isothermal in vitro DNA amplification method. It is one of a series of robust and simple techniques for distinguishing closely related taxa at the species as well as the strain level. RCA is a rapid (requiring less than 1 working day), specific (to the single-nucleotide level), and economical (requiring minimal equipment) tool for fungal screening $(20,21)$.

Previous studies have shown that Trichophyton species have several unique nucleotide positions suitable for the development of specific padlock probes for species characterization; these can be used to distinguishing closely related species (8). In this study, species-specific padlock probes were used to distinguish three species of Trichophyton, T. mentagrophytes, T. rubrum, and T. tonsurans. Using species-specific probes, we correctly identified all clinical isolates. Three standard species of Trichophyton, T. rubrum (CBS 130927), T. mentagrophytes var. interdigitale (NBRC 5812), and T. tonsurans (NBRC 5928) were also positively identified using only the species-specific padlock probes. The sequencing results for the ITS regions of rDNA showed $100 \%$ concordance with the RCA results. Additionally, these results were perfectly concordant with phenotypic identification. The RCA procedure required less than one working day, including DNA extraction, PCR amplification, hybridization, ligation of padlock probes, and RCA amplification, rather than sequencing.

While the results of this study can be applied generally, there were some important limitations. In particular, as mentioned by Kong et al. (8), the specificity of the T. tonsurans probe (Tt-ITS2) is ambiguous because T. equinum is highly closely related. The two species differ by only a single base in the ITS1 region $(7,22)$; therefore, the ITS region does not have sufficient discrimination ability. Designing padlock probes that target other genes, such as $\beta$-tubulin (BT2) and translation elongation factor 1- $\alpha$ (TEF1), may be beneficial. In conclusion, species identification of Trichophyton is important for epidemiological and phylogenetic purposes and for genotype delineation. Despite the shortcomings of current molecular identification systems, there is a strong stimulus for the continued use of ITS polymorphisms to generate identification barcodes. Therefore, the RCA-based assay is an alternative to DNA sequencing for species identification.

\section{Acknowledgements}

We are grateful to the vice-chancellor of research at Mazandaran University of Medical Sciences for financial support. We would like also thank Iman Haghani and Elham Mosayebi for their critical assistance.

\section{Authors' Contributions}

Tahereh Shokohi designed and managed the research. Hamid Badali designed and analyzed the data. Tahereh Shokohi and Mojtaba Didehdar wrote the main manuscript. Hamideh Zakeri collected the samples and performed all tests. Saba Mayahi set up tests and managed the research, and all authors reviewed the manuscript.

\section{Funding/Support}

The present article is based on research done in partial fulfillment of the requirements for the thesis by Hamideh Zakeri, and was financially supported by Mazandaran University of Medical Sciences through grant No. 90 - 14.

\section{References}

1. Kanbe T, Tanaka K. Ultrastructure of the invasion of human hair in vitro by the keratinophilic fungus Microsporum gypseum. Infect Immun. 1982;38(2):706-15.

2. Scher RK, Baran R. Onychomycosis in clinical practice: factors contributing to recurrence. BrJDermatol. 2003;149 Suppl 65:5-9.

3. Weitzman I, Summerbell RC. The dermatophytes. Clin Microbiol Rev. 1995;8(2):240-59.

4. Kanbe T. Molecular approaches in the diagnosis of dermatophytosis. Mycopathologia. 2008;166(5-6):307-17.

5. Makimura K, Tamura Y, Mochizuki T, Hasegawa A, Tajiri Y, Hanazawa R, et al. Phylogenetic classification and species identification of dermatophyte strains based on DNA sequences of nuclear ribosomal internal transcribed spacer 1 regions. J Clin Microbiol. 1999;37(4):920-4.

6. Jackson CJ, Barton RC, Evans EG. Species identification and strain differentiation of dermatophyte fungi by analysis of ribosomalDNA intergenic spacer regions. J Clin Microbiol. 1999;37(4):931-6.

7. Summerbell RC, Moore MK, Starink-Willemse M, Van Iperen A. ITS barcodes for Trichophyton tonsurans and T. equinum. Med Mycol. 2007;45(3):193-200.

8. Kong F, Tong Z, Chen X, Sorrell T, Wang B, Wu Q, et al. Rapid identification and differentiation of Trichophyton species, based on sequence polymorphisms of the ribosomal internal transcribed 


\section{Zakeri H et al.}

spacer regions, by rolling-circle amplification. J Clin Microbiol. 2008;46(4):1192-9.

9. Sun J, Najafzadeh MJ, Zhang J, Vicente VA, Xi L, de Hoog GS. Molecular identification of Penicillium marneffei using rolling circle amplification. Mycoses. 2011;54(6):e751-9.

10. Najafzadeh MJ, Sun J, Vicente VA, de Hoog GS. Rapid identification of fungal pathogens by rolling circle amplification using Fonsecaea as a model. Mycoses. 2011;54(5):e577-82.

11. Davari M, van Diepeningen AD, Babai-Ahari A, Arzanlou M, Najafzadeh MJ, van der Lee TA, et al. Rapid identification of Fusarium graminearum species complex using Rolling Circle Amplification (RCA). J Microbiol Methods. 2012;89(1):63-70.

12. Hamzehei H, Yazdanparast SA, Davoudi MM, Khodavaisy S, Golehkheyli M, Ansari S, et al. Use of rolling circle amplification to rapidly identify species of Cladophialophora potentially causing human infection. Mycopathologia. 2013;175(5-6):431-8.

13. White TJ, Bruns T, Taylor J. Amplification and direct sequencing 8 of fungal ribosomal RNA genes for phylogenetics. In: Innis MA, Gelfand DH, Sninsky JJ, White TJ editors. PCR Protocols : A Guide to Methods and Applications.. London: Academic Press; 1990. pp. 315-22.

14. Faruqi AF, Hosono S, Driscoll MD, Dean FB, Alsmadi O, Bandaru $\mathrm{R}$, et al. High-throughput genotyping of single nucleotide polymorphisms with rolling circle amplification. BMC Genomics.
2001;2:4.

15. Nilsson M. Lock and roll: single-molecule genotyping in situ using padlock probes and rolling-circle amplification. Histochem Cell Biol. 2006;126(2):159-64.

16. Nilsson M, Dahl F, Larsson C, Gullberg M, Stenberg J. Analyzing genes using closing and replicating circles. Trends Biotechnol. 2006;24(2):83-8.

17. Wang B, Potter SJ, Lin Y, Cunningham AL, Dwyer DE, Su Y, et al. Rapid and sensitive detection of severe acute respiratory syndrome coronavirus by rolling circle amplification. J Clin Microbiol. 2005;43(5):2339-44.

18. Fire A, Xu SQ. Rolling replication of short DNA circles. Proc Natl Acad Sci U S A. 1995;92(10):4641-5.

19. Liu D, Daubendiek SL, Zillman MA, Ryan K, Kool ET. Rolling Circle DNA Synthesis: Small Circular Oligonucleotides as Efficient Templates for DNA Polymerases.J Am Chem Soc. 1996;118(7):1587-94.

20. Demidov VV. Rolling-circle amplification in DNA diagnostics: the power of simplicity. Expert Rev Mol Diagn. 2002;2(6):542-8.

21. Yoshimura T, Nishida K, Uchibayashi K, Ohuchi S. Microwave assisted rolling circle amplification. Nucleic Acids Symp Ser (Oxf). 2006(50):305-6.

22. Graser Y, Kuijpers AF, Presber W, De Hoog GS. Molecular taxonomy of Trichophyton mentagrophytes and T. tonsurans. Med Mycol.1999;37(5):315-30. 